\title{
Diversity Barometer 2020: Attitudes towards Immigration and Ethnic Diversity in Sweden
}

\author{
Jimmy Stephen Munobwa ${ }^{1, * \mathbb{D}}$, Fereshteh Ahmadi ${ }^{1} \mathbb{D}$ and Mehrdad Darvishpour ${ }^{2}$ \\ 1 Faculty of Health and Occupational Studies, University of Gävle, 80176 Gävle, Sweden; \\ Fereshteh.ahmadi@hig.se \\ 2 School of Health, Care and Social Welfare, Mälardalen University, P.O. Box 883, 72123 Västerås, Sweden; \\ mehrdad.darvishpour@mdh.se \\ * Correspondence: jimmy.munobwa@hig.se
}

Citation: Munobwa, Jimmy Stephen, Fereshteh Ahmadi, and Mehrdad Darvishpour. 2021. Diversity Barometer 2020: Attitudes towards Immigration and Ethnic Diversity in Sweden. Social Sciences 10: 401. https://doi.org/10.3390/ socsci10100401

Academic Editor: Nigel Parton

Received: 26 August 2021

Accepted: 29 September 2021

Published: 19 October 2021

Publisher's Note: MDPI stays neutral with regard to jurisdictional claims in published maps and institutional affiliations.

Copyright: (C) 2021 by the authors Licensee MDPI, Basel, Switzerland. This article is an open access article distributed under the terms and conditions of the Creative Commons Attribution (CC BY) license (https:/ / creativecommons.org/licenses/by/ $4.0 /)$.

\begin{abstract}
Migration is topical in many counties, and attitudes towards immigration and ethnic diversity are volatile. In our longitudinal "Diversity Barometer", we have studied changes in Swedes" attitudes towards immigration and ethnic diversity in Sweden since 2005, using a postal questionnaire sent to a random sample of the Swedish population aged 18-75. In this article, we analyzed data from 2020 ( $n=1035)$ in comparison with previous Diversity Barometer surveys from 2005 to 2018. The findings showed that Swedes had increased contact with immigrants from the Middle East, Asia and Africa. The majority had good experiences of studying or working with people with foreign background, although those with bad experiences had also increased. Attitudes towards immigration and ethnic diversity were more positive in 2020, thereby stopping a negative trend that started with the refugee influx in 2015. Positive attitudes were more established among women, younger people, those with higher education, people living in larger cities and those with more contact with people with foreign background. Sympathizers of political parties closer to the left wing were more positive towards immigration and ethnic diversity. We used political correctness, contact theory, strain theory and theory about group conflict/threats to provide hypothetical explanations for the observed changes in attitudes.
\end{abstract}

Keywords: Diversity Barometer; migration; Sweden; xenophobia; strain theory; contact theory; group conflict theory

\section{Introduction}

Attitudes towards immigration and ethnic diversity have been topical and controversial over many decades, with studies showing both positive and negative attitudes (Holloway and Leach 2020; Novus 2014; Schütze 2020). Migration has become more important than before on the political agenda and Sweden's previous exemplary image on humanitarian policies has changed (Asztalos Morell and Darvishpour 2018; Crawley and Mcmahon 2016; Darvishpour and Westin 2021). In Sweden, the Diversity Barometer studies have been conducted since 2005 to examine attitudes towards immigration and ethnic diversity (Ahmadi et al. 2015, 2020a, 2020b). The Diversity Barometer is a survey of Swedes' attitudes towards immigration and ethnic diversity. Researchers at the Department of Sociology, Uppsala University developed the Diversity Barometer in 2005. In 2013, the University of Gävle took over responsibility for the Diversity Barometer. Between 2005 and 2014, the Diversity Barometer surveys were conducted annually; thereafter, biennial surveys were conducted. A standardized questionnaire was used to enable comparisons over the years. Authors of this article have been involved in varying degrees since the beginning.

The studies show a positive trend in Swedes' attitudes towards immigration and ethnic diversity up to 2014 (Ahmadi et al. 2015). The subsequent studies in 2016 and 2018 show increased negativity towards immigration and ethnic diversity, explained by the refugee crisis in 2015 when Sweden received many refugees from the Middle East (Ahmadi et al. 
2020a, 2020b). Negative public and political discourse about refugees, and restrictive immigration policies in Sweden are also attributed to the refugee crisis in 2015 (Hagelund 2020). The majority of respondents believed that there was too much immigration; protectionism and securitization characterized Sweden's response after the 2015 refugee crisis (Ericson 2018).

Attitudes towards ethnic diversity and immigration remain volatile. There is continued internationalization of far-right activities, and far-right organizations and sympathizers in Sweden easily connect with like-minded people in other parts of the world (Crawley and Mcmahon 2016; Mulhall and Khan-Ruf 2021). Moreover, there is a thin line between discussions of immigration and race, and the "Black Lives Matter" movement led the far right to talk freely about race politics, which they previously disguised as cultural nationalism (Mulhall and Khan-Ruf 2021). There is acknowledgement that immigrants, including refugees, are a necessary resource that can boost Sweden's economy. However, political and media discourse has focused on the shortcomings of Swedish immigration policies. This discourse has negatively affected public opinion on immigration and ethnic diversity. Sweden has thus experienced a steady increase in party sympathy for anti-immigration/nationalistic far-right organizations, with the number of the Sweden Democrats' parliamentary representatives growing from $20(5.7 \%)$ in 2010 to $62(17.5 \%)$ in 2018 to become the third largest party in the Swedish parliament (Valmyndigheten 2021).

Sweden has had a generous migration policy for a relatively long time. Today, immigrants make up a significant portion of the Swedish population. A total of $19.7 \%$ of the population is born out of Sweden and 23\% have a foreign background (Statistics Sweden 2021). Sweden has a public welfare system intended to cover the entire population, including immigrants with the right to reside in Sweden (Schütze 2020). However, social exclusion of immigrants is visible; Schütze (2020, p. 425) explains, "despite this formal inclusion of migrants, many studies indicate that migrants are facing different forms of exclusion; for instance, through ethnic segregation, discrimination on the labor market and the rental housing market". Studies by Ahmed and Hammarstedt (2008), Bursell (2012) and Aldén et al. (2015) indicate the existence of ethnic discrimination and segregation on the labor and rental housing market. Attitudes towards migrants and ethnic diversity directly influence how migrants are treated within the welfare systems; negative attitudes are associated with unequal treatment (Dias et al. 2012; Pitkänen and Kouki 2002; Schütze 2020). Some of the aforementioned studies, although from different contexts, indicate trends that are applicable in the Swedish context.

Sweden is facing augmentation of far-right/anti-immigration political parties and groups, which jeopardizes the Swedish welfare policy. Sweden is simultaneously experiencing a steady increase in persons with foreign backgrounds. Extreme attitudes towards ethnic diversity risk increasing polarization and tensions between different groups in the Swedish population, which in turn may complicate integration and cohesion. The political climate has become volatile and attitudes towards immigration and ethnic diversity in Sweden and many other countries in the West are in constant change. Studies of attitudes towards migration are thus important in providing insight into welfare policy outcomes, as well as areas for further research (Schütze 2020). The Diversity Barometer studies serve this purpose, in addition to investigating Swedes' attitudes towards migration and ethnic diversity. This article, based on the Diversity Barometer studies, is therefore relevant for researchers and policy makers in Sweden and other countries facing similar immigration-related dilemmas.

Our aim in this article is to examine changes in attitudes towards immigration and ethnic diversity in Sweden. We do so by analyzing data from 2020 in comparison with results from the previous Diversity Barometer studies.

\section{Materials and Methods}

We have conducted the Diversity Barometer studies since 2005, to understand attitudes towards immigration and ethnic diversity. Since 2016, we have collected data biennially through a survey of adults aged between 18 and 75 years old living in Sweden. This paper focuses 
on the Diversity Barometer study of 2020. We collected data over five weeks between May and June 2020, using a postal questionnaire. The questionnaire covered three main topics: (1) experiences of contact with people with foreign backgrounds, (2) general positive attitudes towards immigration and diversity, and (3) general negative attitudes towards immigration and diversity.

We collected the data from a randomly selected sample based on the Swedish Population Register (SPAR), which is a public register of all people registered as residents in Sweden. We sent the questionnaire to 5000 individuals, of whom 1035 returned the filled-out questionnaire (21\% response rate). With a net sample size of 1035 , the margin of error for a result of $50 \%$ is rounded to $+/-3 \%$. This implies that the true result for the population, at a confidence level of $95 \%$, lies within the interval $47-53 \%$. Results of approximately $10 \%$ or $90 \%$ have a margin of error rounded to $+/-2 \%$, which means that the true result for the population, at a confidence level of $95 \%$, lies within the interval $8-12 \%$ or $88-92 \%$.

Female respondents were overrepresented (54\%) in comparison to the official population statistics from Statistics Sweden-SCB for 2019 (49\%). Inversely, male respondents were underrepresented. Respondents with university education were overrepresented (50\%) when compared to the official population statistics for 2019 (46\%). Respondents with high school education were slightly underrepresented (39\%), while the percentage of respondents with primary and lower secondary education (11\%) was representative of the Swedish population. Figure 1 provides a summarized description of the sample.

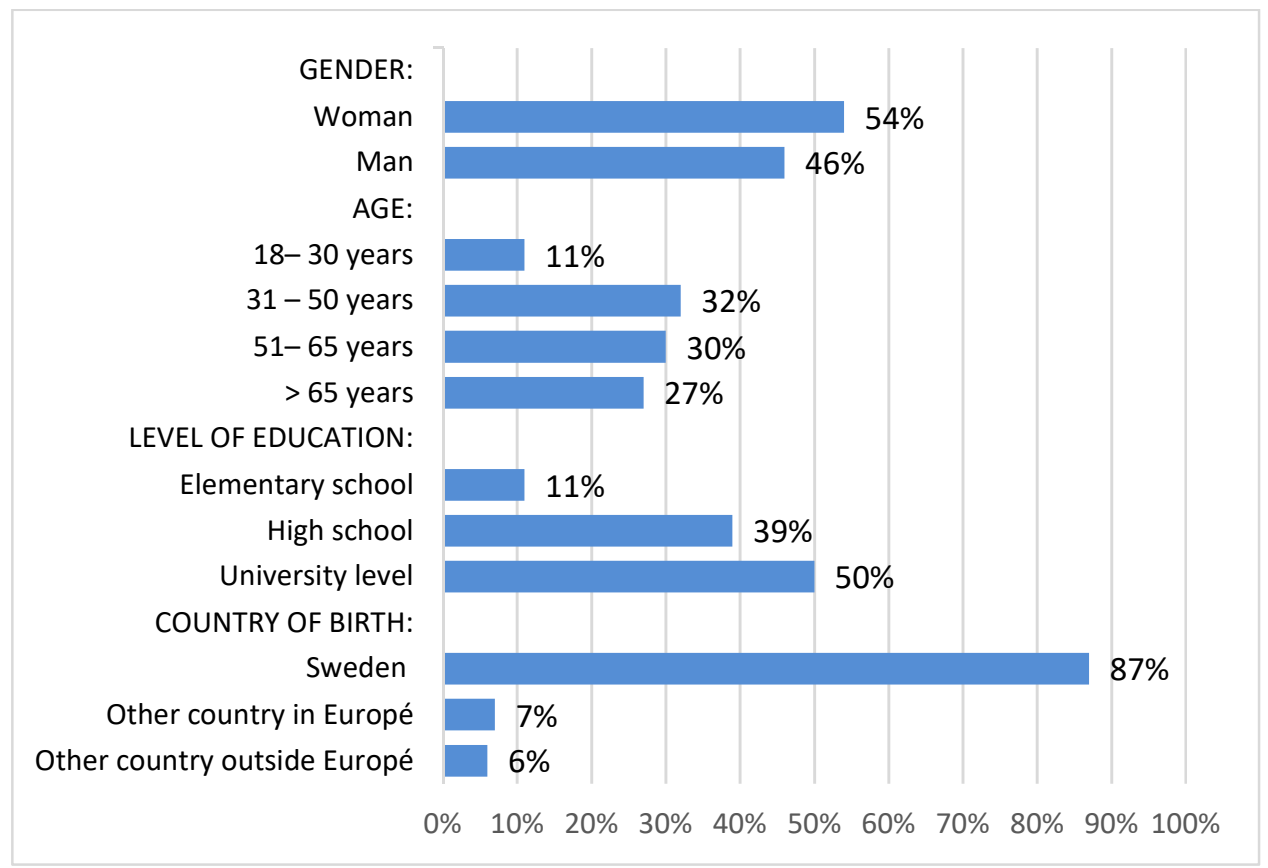

Figure 1. Description of the sample $2020(n=1035)$.

The sample had more older respondents than younger ones when compared to official statistics for 2019. As shown in Figure 2, the age groups 50-65 years and 65-75 years were overrepresented, while the reverse is true for the younger age groups. Notably, respondents aged $65-75$ years comprised $27 \%$ of the sample, yet $15 \%$ of the official population statistics. Additionally, respondents aged 18-30 years comprised $11 \%$ of the sample, yet $23 \%$ of the official population statistics. The discrepancies related to sex, education level and gender could potentially affect the results of this study. However, they could also have a counterbalancing effect on each other. For example, there was an overrepresentation of females and highly educated respondents. These groups are normally more positive to 
diversity. On the other hand, older respondents, who are normally more negative toward diversity, were overrepresented.

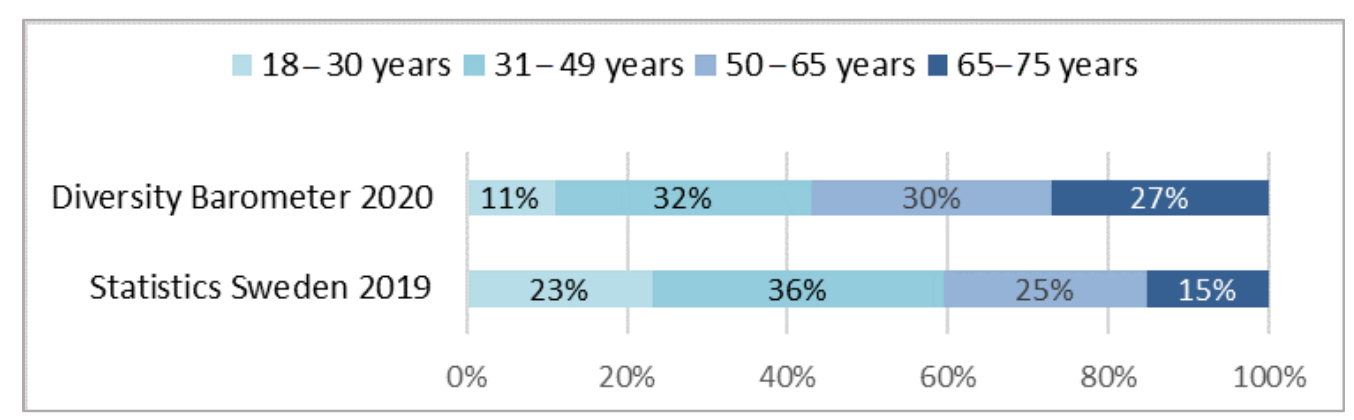

Figure 2. Age distribution: A comparison between the Diversity Barometer 2020 sample $(n=1035)$ and the actual distribution of the Swedish population aged 18-75 years in 2019, also labeled as statistics Sweden 2019 in this figure (Statistics Sweden n.d.).

The sample has high representativeness in relation to political party sympathy: Swedish Social Democratic Party (S) - 33\%, Moderate Party (M) - 18\%, Sweden Democrats (SD) - 17\%, Left Party (V)—10\%, Centre Party (C)—7\%, Green Party (MP)—6\%, Christian Democrats (KD) $-6 \%$, and Liberals (L) - $3 \%$. Nineteen percent (19\%) are unsure which party they would vote for in a parliamentary election. Eighty seven percent $(87 \%)$ of the respondents were born in Sweden, which reflects a slight overrepresentation. Seven percent $(7 \%)$ were born in another European country, while $6 \%$ were born outside Europe.

With a sample size of 1035 respondents for this study ( $21 \%$ response rate), the margin of error for a result of $50 \%$ is rounded to $+/-3 \%$ units, which means that the true result for the actual population with $95 \%$ certainty is found in the range of $47-53 \%$. Results of approximately $10 \%$ or $90 \%$ have a margin of error rounded to $+/-2 \%$ units, which means that the true result for the entire population with $95 \%$ certainty is found in the range of $8-12 \%$ or $88-92 \%$.

\section{Results}

\subsection{Experience of Contact with People with Foreign Backgrounds}

The results showed that the respondents experienced contact with people from the Nordics and other European countries more often than contact with people from the rest of the world. Forty nine percent $(49 \%)$ of the respondents had at least monthly contact with people from other Nordic countries or other European countries. However, this result indicated a decrease in comparison to 2018 , where $54 \%$ and $52 \%$ of the respondents, respectively, had at least monthly contact with people from the Nordics or other European countries.

Conversely, contact with people from non-European countries increased with the exception of Latin America, North America, and Australia. Forty one percent (41\%) of the respondents had at least monthly contact with people from the Middle East. The corresponding result for 2018 was $35 \%$. Respondents experiencing at least monthly contact with people from Asia and Africa also increased by $5 \%$ to $30 \%$ and $24 \%$, respectively. On the contrary, the percentage of respondents experiencing at least monthly contact with people from Latin America reduced by $4 \%$ to $18 \%$ in comparison to the results from 2018 . The results further showed that the respondents had the least contact with people from North America and Australia, which was in line with the results from 2018 and 2016 (see Figure 3).

There was no difference between male and female respondents concerning the frequency of interaction with people of a non-European background. Swedes in all age groups up to 65 years had more frequent contact with people of a non-European background, as compared to the Swedes above 65 years. 


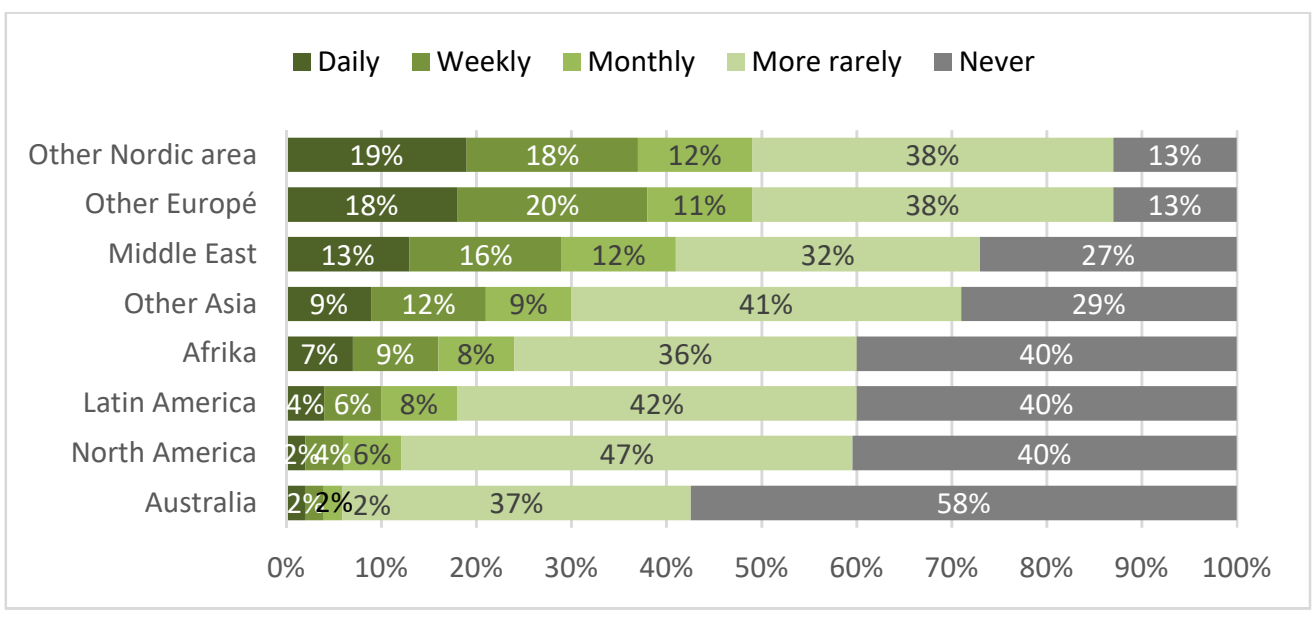

Figure 3. Frequency of socializing with people from other parts of the world $(n=1035)$.

The percentage of respondents with good or very good experiences of working or studying with colleagues with foreign backgrounds was 74\%, equaling the result from 2018. This result, together with the result from 2018, was the highest ever recorded. Over the long term, the results show a sustained increase in positive experiences (see Figure 4).

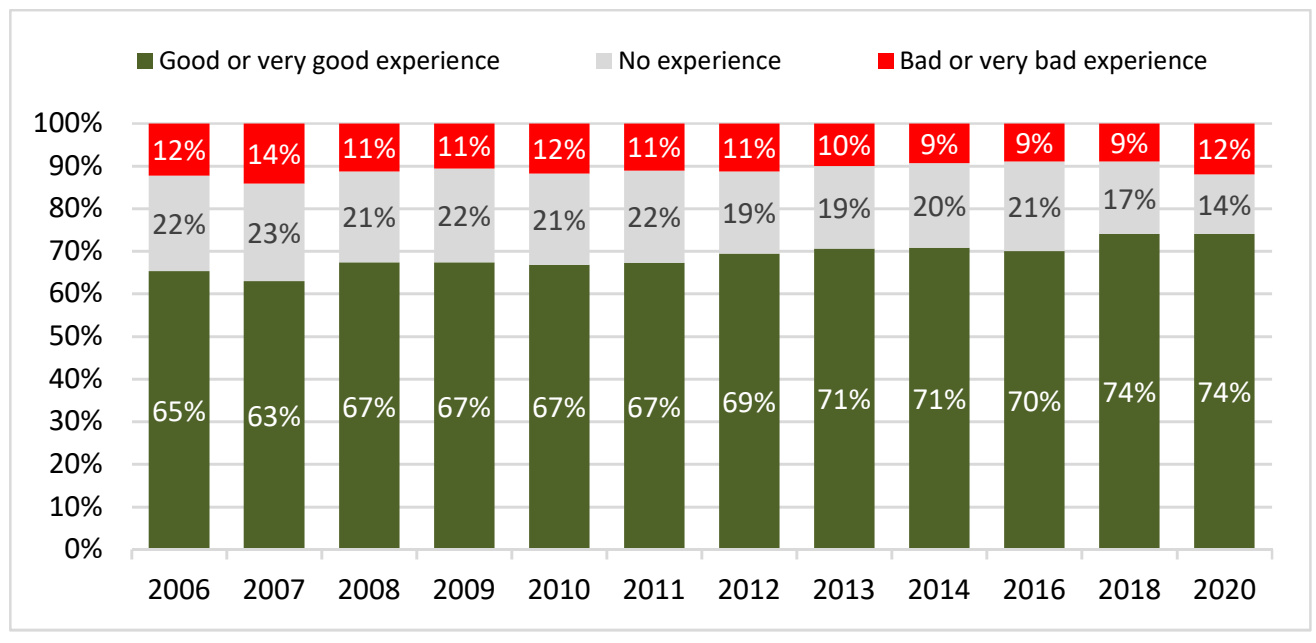

Figure 4. Experiences from working/studying with people with foreign background.

Considering political party sympathy, more that $74 \%$ of sympathizers of all political parties apart from the Sweden Democrats (SD) reported good or very good experiences of working or studying with colleagues with foreign backgrounds. Notably, only $42 \%$ of SD sympathizers reported good or very good experiences, while 36\% reported bad or very bad experiences. Generally, sympathizers of political parties closer to right-wing politics reported less positive experiences of working or studying with colleagues with foreign backgrounds (see Figure 5). The other parties in the figure are the Moderate Party (M), the Christian Democrats (KD), the Liberals (L), the Centre Party (C), the Green Party (MP), the Social Democratic Party (S) and the Left Party (V). 


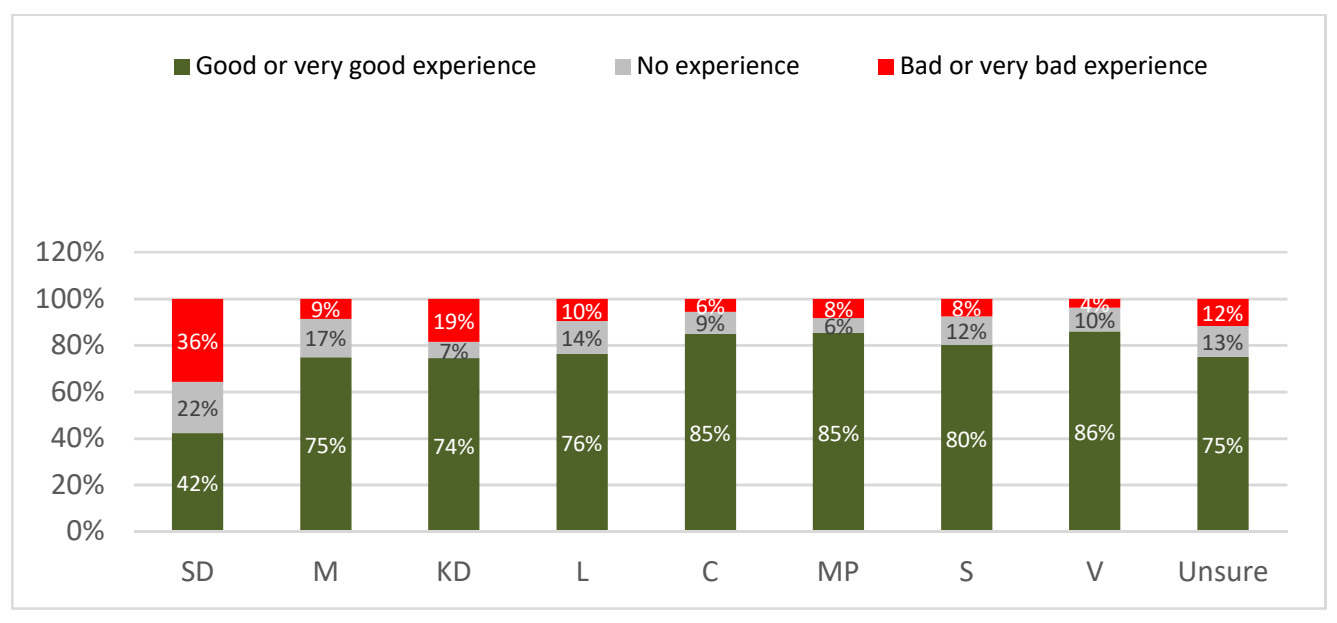

Figure 5. Experiences from working/studying with people with foreign background $(n=1035)$.

\subsection{Positive Attitudes towards Immigration and Ethnic Diversity}

\subsubsection{Three Positive Statements about Immigration and Ethnic Diversity}

In this section, we present the respondents' attitudes related to three positive statements about the rights and opportunities for newly arrived immigrants and their children in Sweden: (1) the opportunity to preserve their cultural traditions, (2) the same social rights as Swedish citizens, and (3) the opportunity to preserve their native language.

The majority of respondents $(58 \%)$ totally or partly agreed with the statement "the Swedish society should create opportunities for people with foreign backgrounds to preserve their cultural traditions". This result was a departure from the negative trend observed between 2016 and 2018, when the Diversity Barometer recorded the lowest percentage of respondents ( $46 \%$ ) with positive attitudes towards cultural diversity. Additionally, the percentage of respondents who totally or partly disagreed with cultural diversity returned to a relatively normal level (28\%) in 2020, after a record high $39 \%$ in 2018 (see Figure 6).

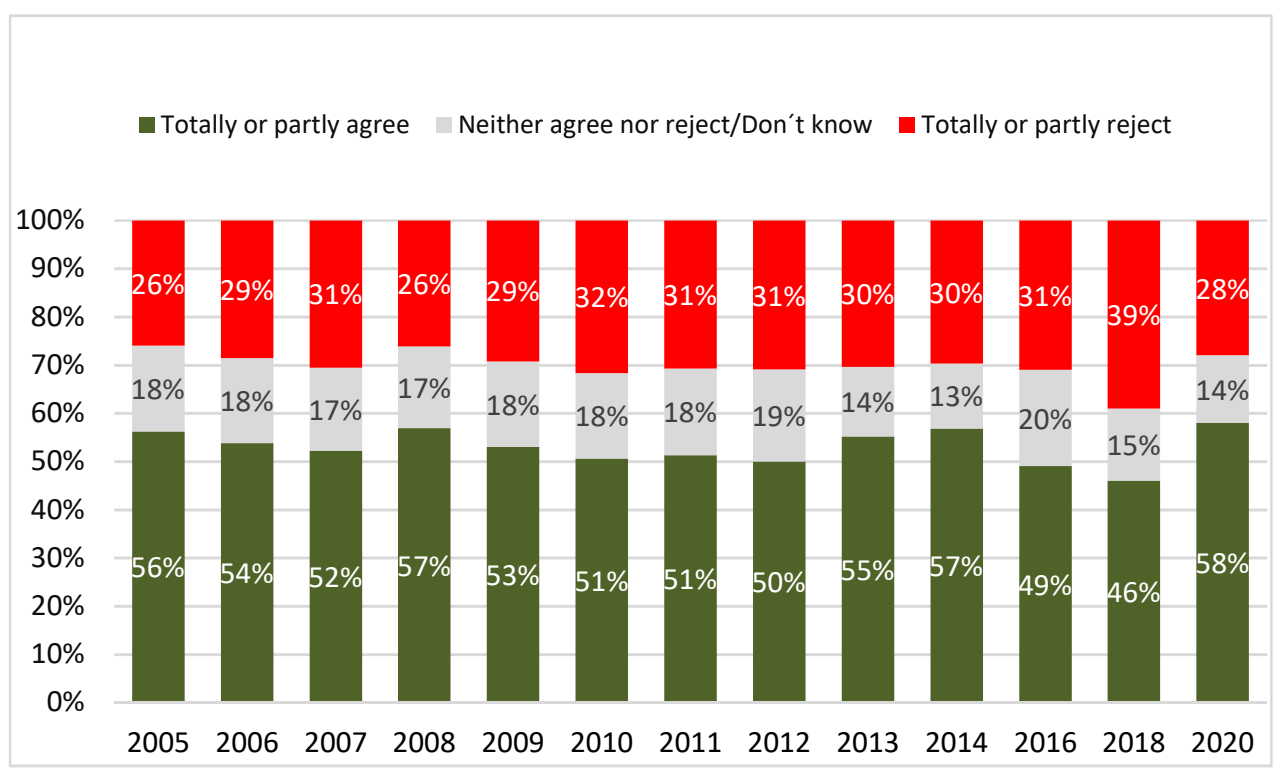

Figure 6. Positive statement about preservation of cultural traditions: The society should create possibilities for people with foreign background to be able to preserve their cultural traditions.

From 2005 up to 2014 , more than $70 \%$ of the respondents totally or partly agreed with the statement "immigrants should have the same social rights as Swedish citizens". The 
highest percentage was recorded in 2014, when 77\% were positive towards equal social rights. However, this trend changed in 2016, with a record low of 55\% of the respondents expressing positive attitudes towards equal social rights. Since then, there has been a gradual increase in positivity towards equal social rights, and the results from 2020 showed that $68 \%$ of the respondents supported equal social rights for immigrants (see Figure 7 ).

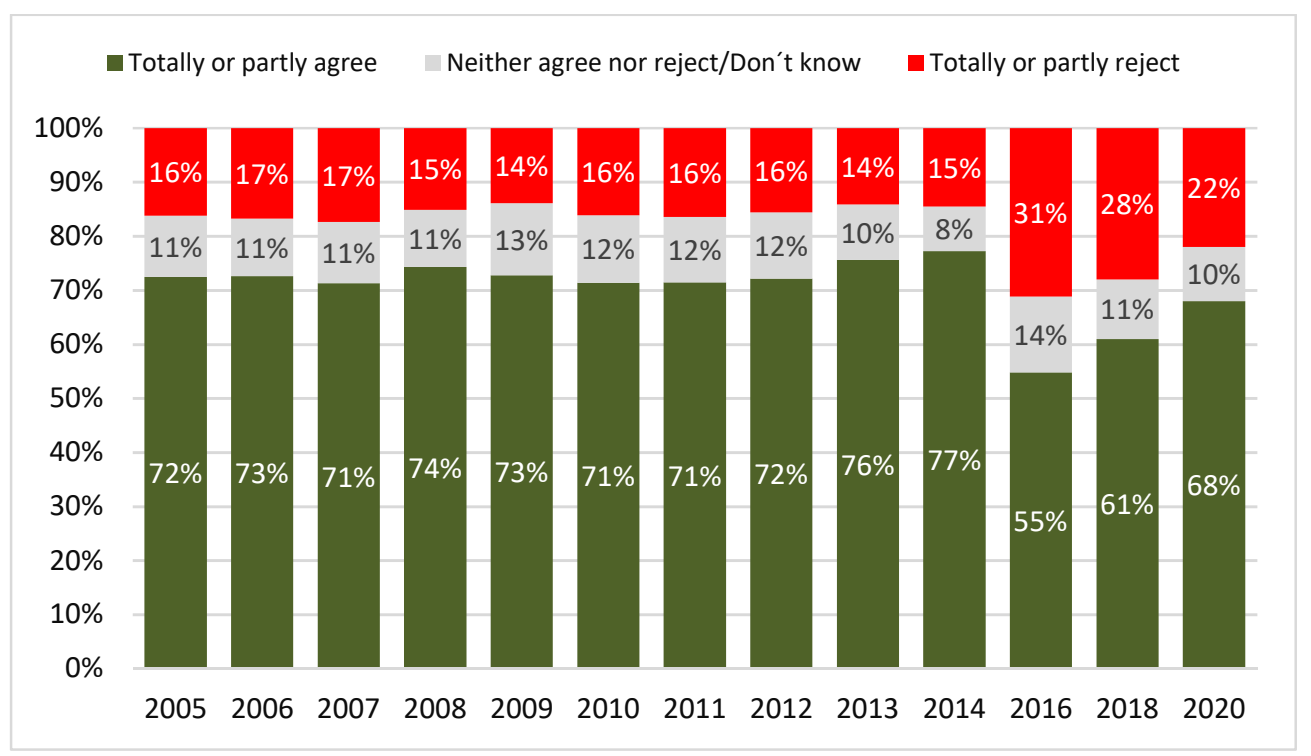

Figure 7. Positive statement about equal social rights: All people with foreign background who come to Sweden must have the same social rights as Swedes.

Since the inception of the Diversity Barometer in 2005, the majority of respondents totally or partly agreed that it is good for immigrants to preserve and teach their native language to their children. The latest results showed a 5\% increase from 56\% in 2018 to $61 \%$ in 2020 , although the results were within the stable range of $56-61 \%$ recorded since 2005. The percentage of respondents against preservation of immigrants' native language has been stable over the years between 19\% and 24\% (see Figure 8).

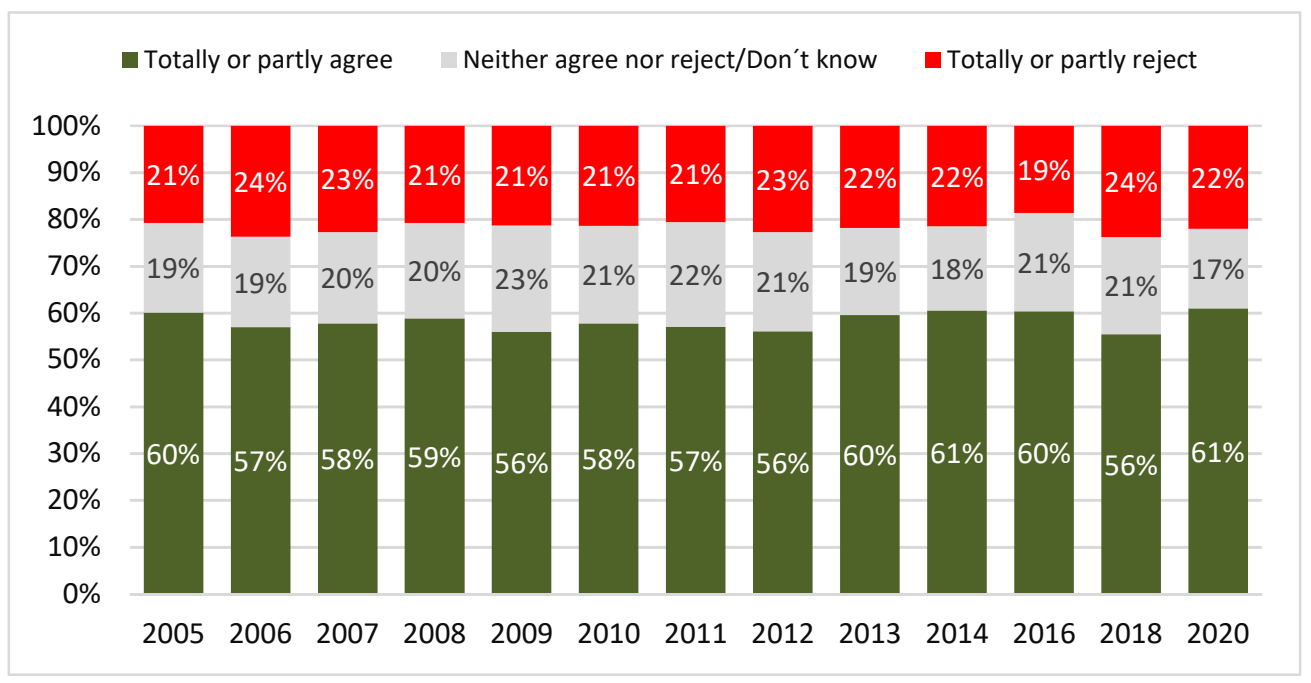

Figure 8. Positive statement about preservation of native language: It is good that all people with foreign background who come to Sweden keep their native language and teach their children the language. 


\subsubsection{Positive Diversity Index}

We created a positive diversity index for each of the three positive statements about ethnic diversity. The index (0-4) enables comparison of the three statements with each other, and analysis of attitude trends over time. The higher the index, the more positive the attitudes towards ethnic diversity.

Generally, the respondents were most positive towards equal social rights (2.8), followed by preservation of native language (2.7) and lastly preservation of culture for immigrants (2.3). Figure 9 shows a stable level of positive attitudes since the inception of the Diversity Barometer. After a slight dip in 2016, attributed to the 2015 refugee crisis, the positive diversity indices gradually increased to equal previously stable levels. The only exception was the positive diversity index on equal social rights, which also increased but did not equal the average of 3.0 registered prior to 2016.

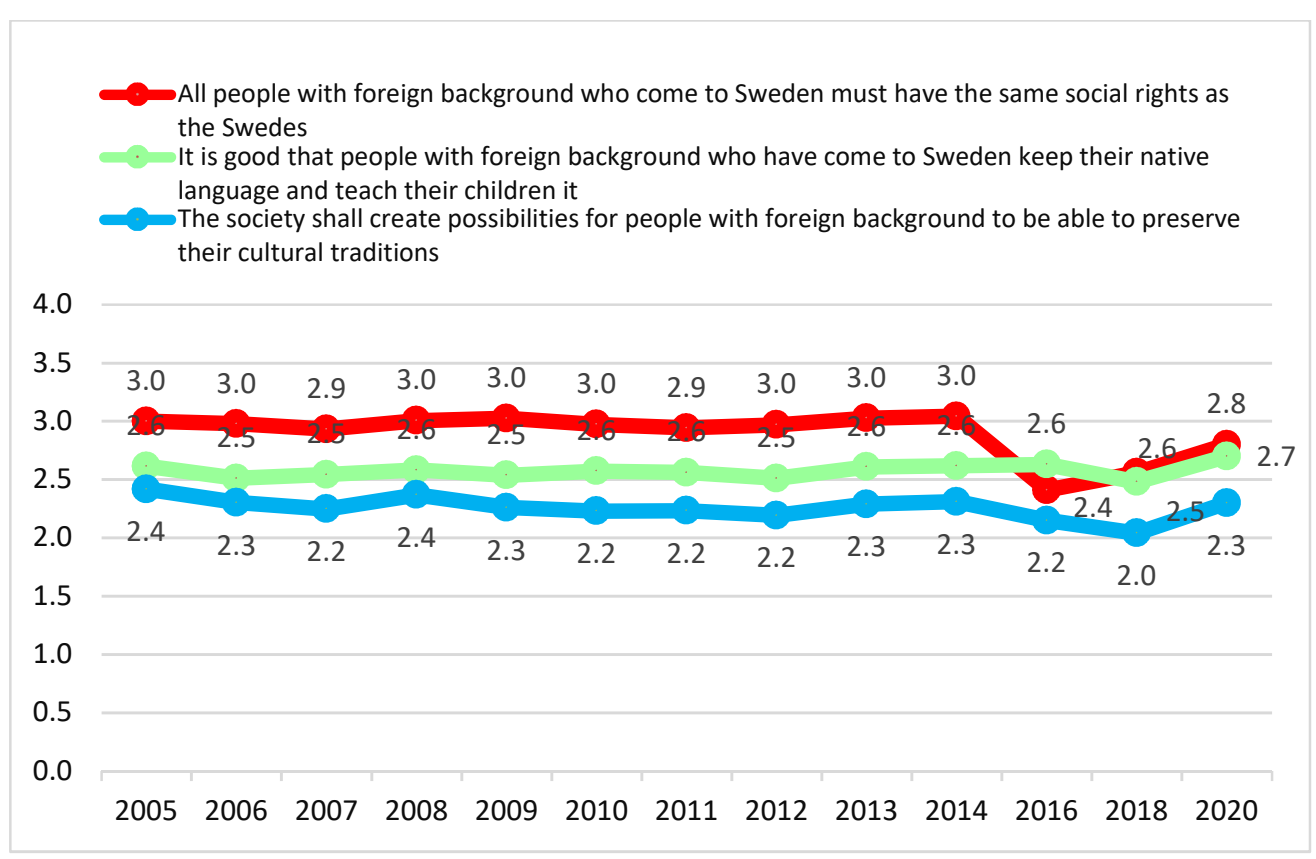

Figure 9. Three positive diversity indices (0-4) based on the three positive statements about diversity.

\subsection{Negative Attitudes towards Immigration and Ethnic Diversity}

3.3.1. Three Negative Statements about Immigration and Ethnic Diversity

In this section, we present data related to three negative statements about immigration and ethnic diversity: (1) all people with foreign backgrounds who commit crime should be deported from Sweden; (2) many people with foreign backgrounds come to Sweden to take advantage of the country's generous social welfare benefits; and (3) native Swedes feel greater responsibility for their work than people with foreign backgrounds do.

The most negative attitudes towards ethnic diversity related to the deportation of people with foreign backgrounds who commit crime ins Sweden. Since the inception of the Diversity Barometer, an average of $60 \%$ of respondents agreed with the statement. We observed a decreasing trend in positive attitudes between 2016 and 2018, when 64-66\% of respondents totally or partly agreed with the statement. However, the results from 2020 $(62 \%)$ showed a slight improvement and a return to average levels (see Figure 10).

Since 2013, there was a gradual increase in the percentage of respondents who totally or partly agreed with the statement that many people with foreign backgrounds come to Sweden to take advantage of the country's generous social welfare benefits. The results from 2020 show that $44 \%$ agreed with this statement. It is noteworthy that this negative statement divided the respondents into two halves, with an almost equal percentage (38\%) 
who disagreed with the statement. As shown in Figure 11, this trend has persisted since the beginning of the Diversity Barometer in 2005.

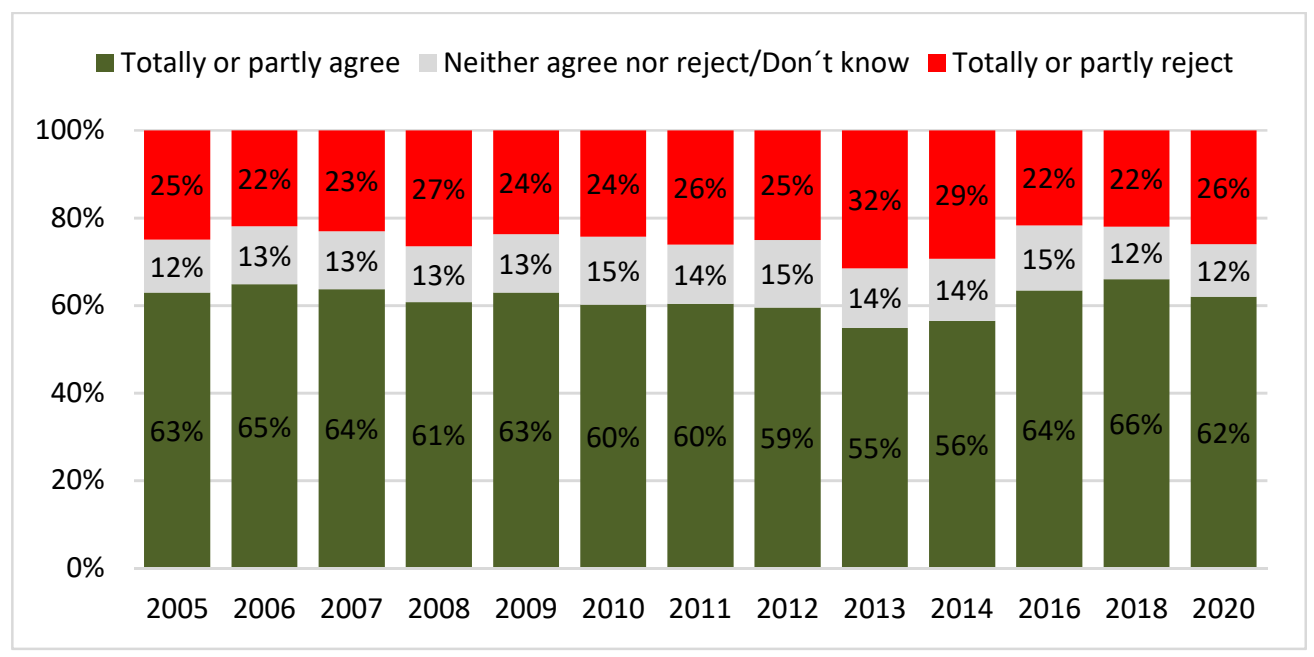

Figure 10. Negative statement about deportation if convicted: All people with foreign background who commit crime should be deported from Sweden.

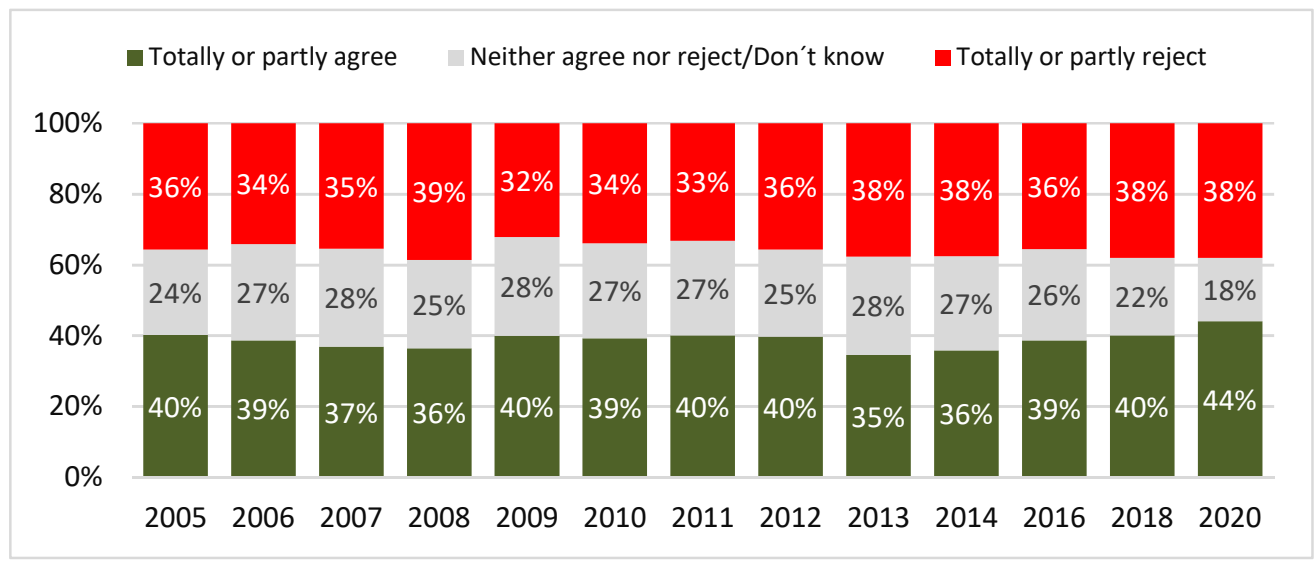

Figure 11. Negative statement about exploitation of social benefits: many people with foreign background come to Sweden to exploit the Swedish social welfare benefits.

In $2020,17 \%$ of the respondents agreed totally or partly with the statement that native Swedes feel greater responsibility for their work than people with foreign backgrounds do. Attitudes related to this statement were stable since 2005, although there was a slight decrease in positivity in 2016, as illustrated in Figure 12. It is noteworthy that the results from 2020 also represented the lowest percentage (47\%) of respondents who rejected the statement. Moreover, as many as 37\% of the respondents in 2020 neither agreed nor disagreed with this statement.

\subsubsection{Negative Diversity Index}

We created a negative diversity index (0-4) for each of the negative statements about ethnic diversity. The higher the index, the more negative the attitudes of the respondents. The results from 2020 showed that the statement about crime and deportation has the highest index (2.6), followed by exploitation of social welfare benefits (2.0). The statement about native Swedes feeling greater responsibility for their work had the lowest index (1.4). The indices on exploitation of social welfare benefits and responsibility for work showed a slight increase in 2020, but were still within the stable range of 1.9-2.0 and 1.1-1.4, 
respectively (see Figure 13). The index on crime and deportation reduced to 2.6 after a record high of 2.7 in 2016 and 2018.

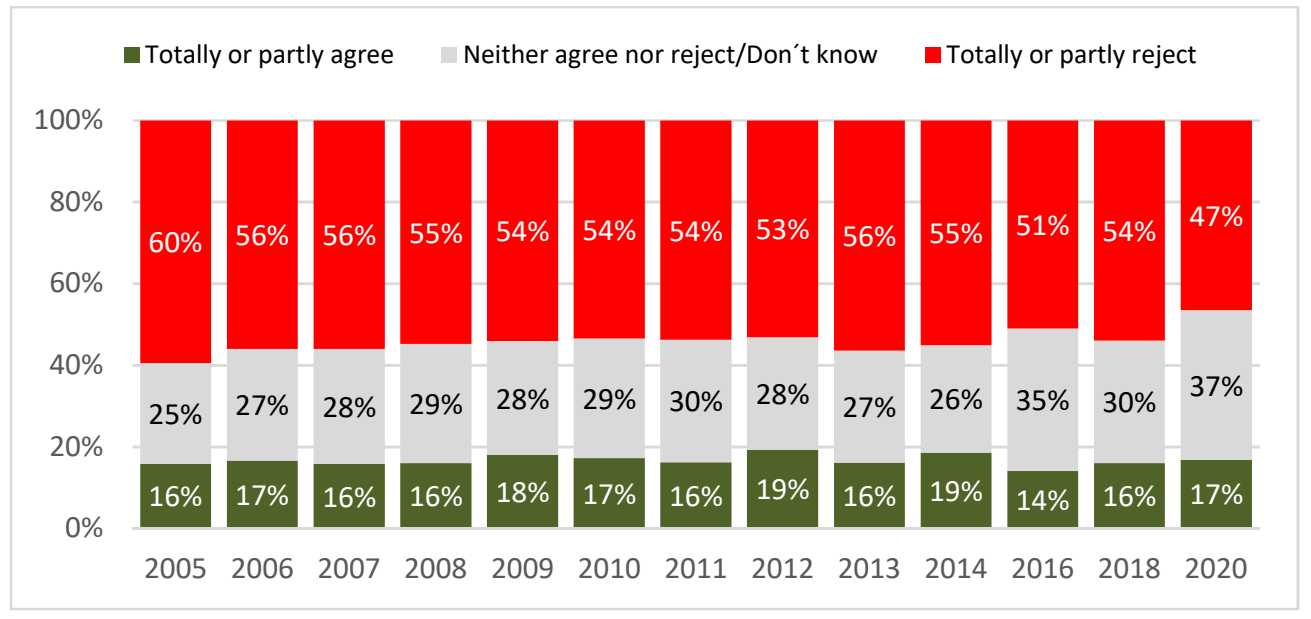

Figure 12. Negative statement about responsibility at work: Swedes have greater responsibility towards their job compared to people with a foreign background.

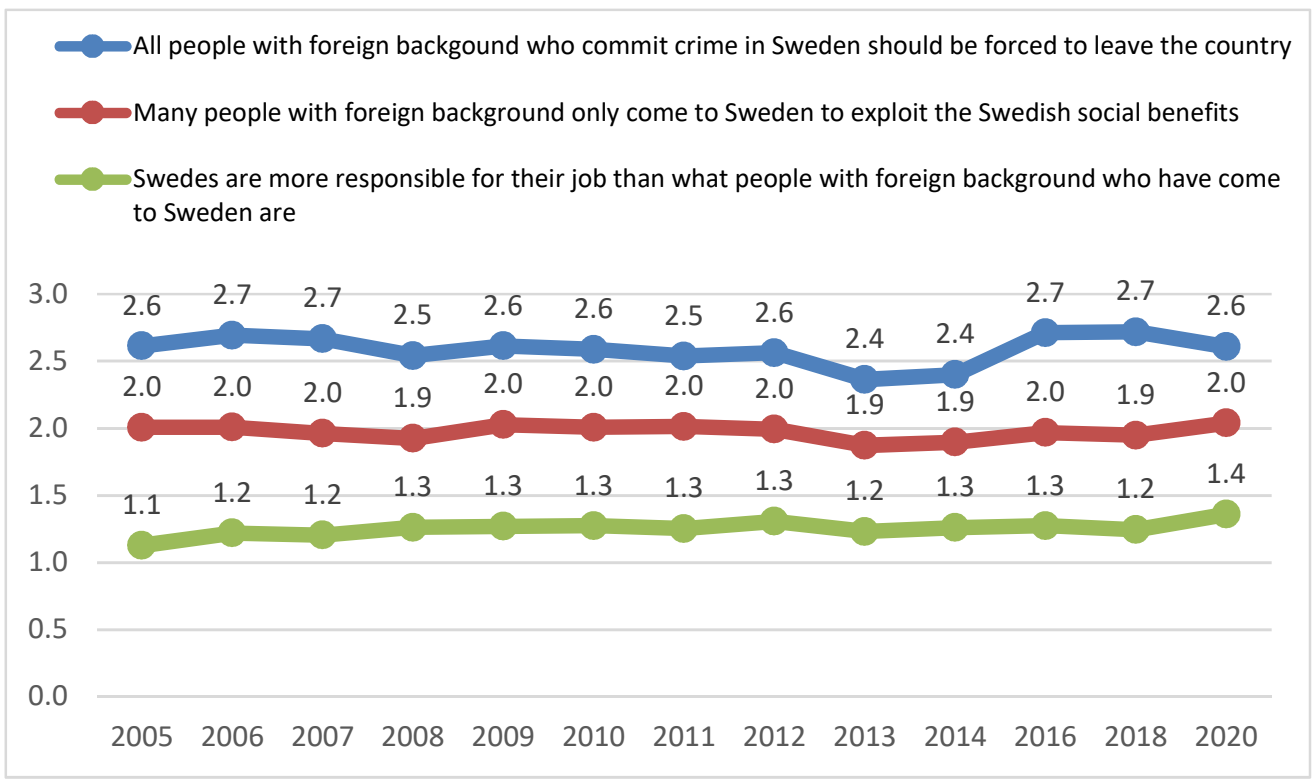

Figure 13. Three negative diversity indices (0-4) based on the three negative statements about diversity.

The majority of respondents totally or partly agree with the statement that all people with foreign backgrounds who commit crime should be deported. Historically, female and male respondents had an identical index ranging between 2.3 and 2.8. However, the results from 2020 showed an emerging trend where male respondents were more negative (2.7 for males compared to 2.5 for females). Additionally, males were more negative than females on attitudes about immigrants exploiting social welfare benefits (2.2 and 1.9, respectively) and feeling less responsibility for their work compared to Swedes (1.6 and 1.1, respectively).

\subsection{General Diversity Index on Attitudes towards Immigration and Ethnic Diversity}

We created the general index on attitudes towards immigration and ethnic diversity by combining the three positive and three negative statements mentioned above. The index has a minimum value of 0 and a maximum value of 4 . The higher the value, the more positive the attitudes towards immigration and ethnic diversity. The general index value 
for 2020 was 2.1, an improvement compared to 2016 and 2018 (1.8 and 1.7, respectively). However, the index value was still lower than the highest ever noted (2.5 in 2013 and 2014). There was a negative trend in attitudes towards immigration and ethnic diversity after the 2015 refugee crisis. However, the results from 2020 seemed to stop this negative trend, as shown in Figure 14.

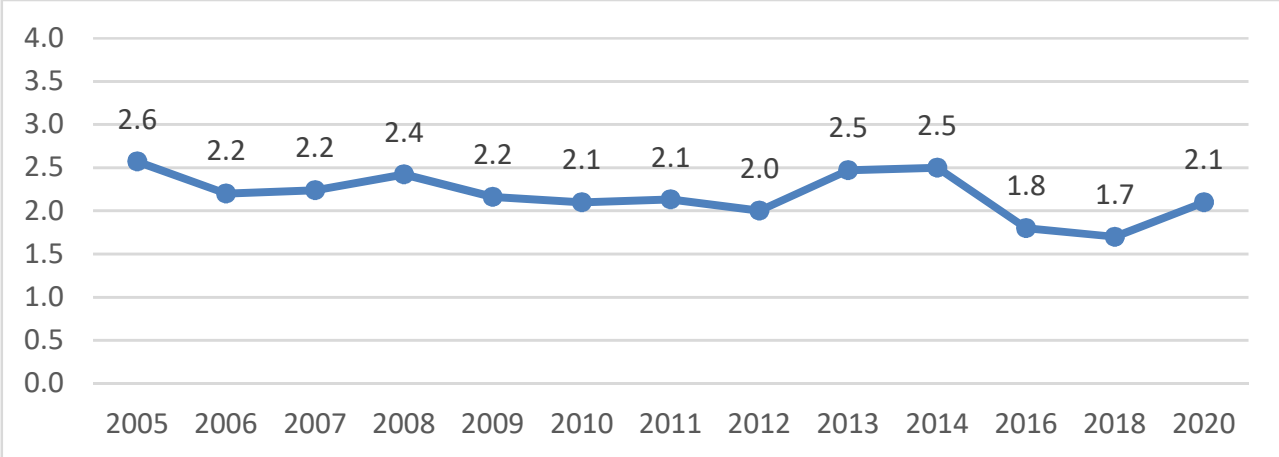

Figure 14. The General Diversity Index based on three weighted positive and three weighted negative statements about diversity.

Female respondents, more than males, were more positive towards immigration and ethnic diversity, a consistent trend since the beginning of the Diversity Barometer studies. Moreover, we observed increased polarization between females and males. Whereas the 2020 index value for females increased to 3.2, the index value for males reduced to 0.9, as shown in Figure 15. Thus, the increased positivity towards immigration and ethnic diversity seemed solely due to improved attitudes among female respondents.

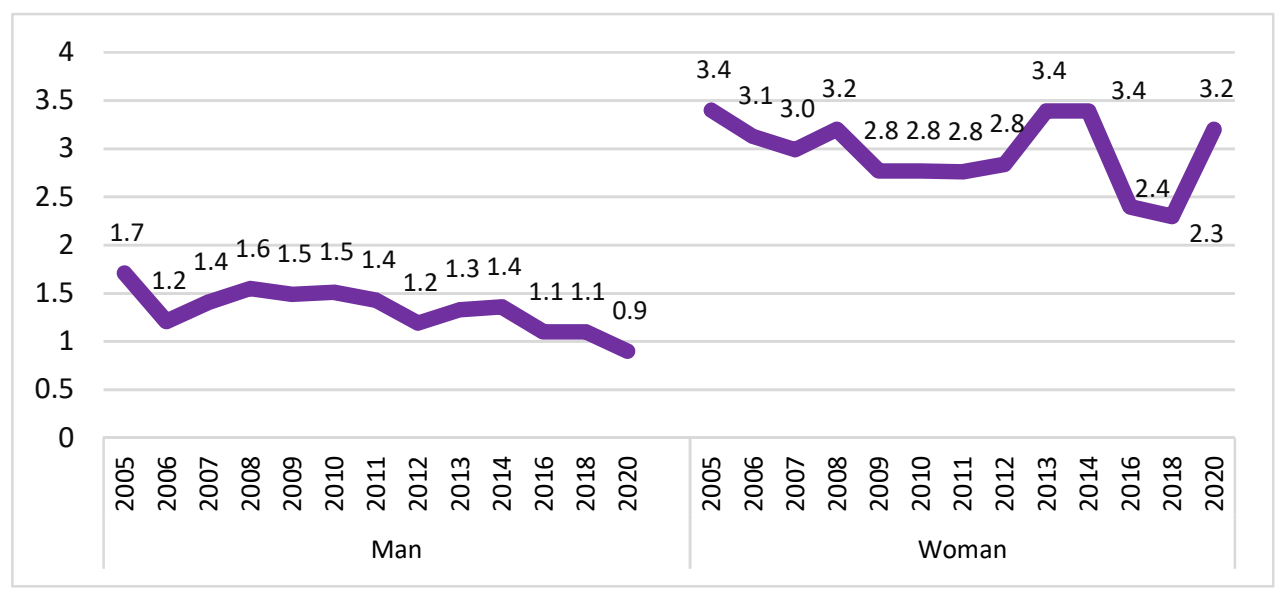

Figure 15. The General Diversity Index based on three weighted positive and three weighted negative statements about diversity—according to gender.

In line with the trend observed since the beginning of the Diversity Barometer in 2005, the results from 2020 showed that respondents with university education were the most positive towards immigration and ethnic diversity. Respondents with the lowest level of education were least positive, as shown in Figure 16. Nevertheless, respondents with university education showed a downward spiral, while the rest showed a positive trend towards more favorable attitudes on immigration and ethnic diversity (see Figure 16).

The younger the respondents, the more positive they were towards immigration and ethnic diversity (see Figure 17). This was in line with the trend since the beginning of the Diversity Barometer. However, unlike all other age groups that showed a positive trend, 
results from 2020 showed that the youngest age group (18-30 years) became more negative, although not as negative as the other age groups (see Figure 17).

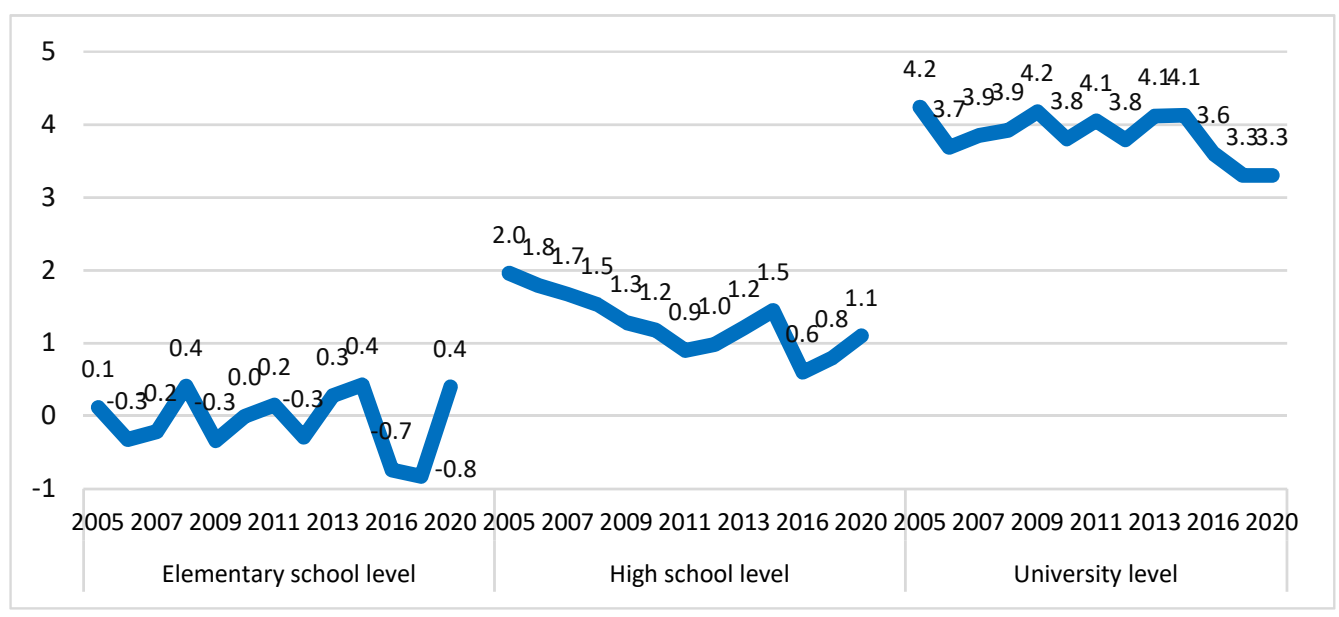

Figure 16. The General Diversity Index based on three weighted positive and three weighted negative statements about diversity-according to level of education.

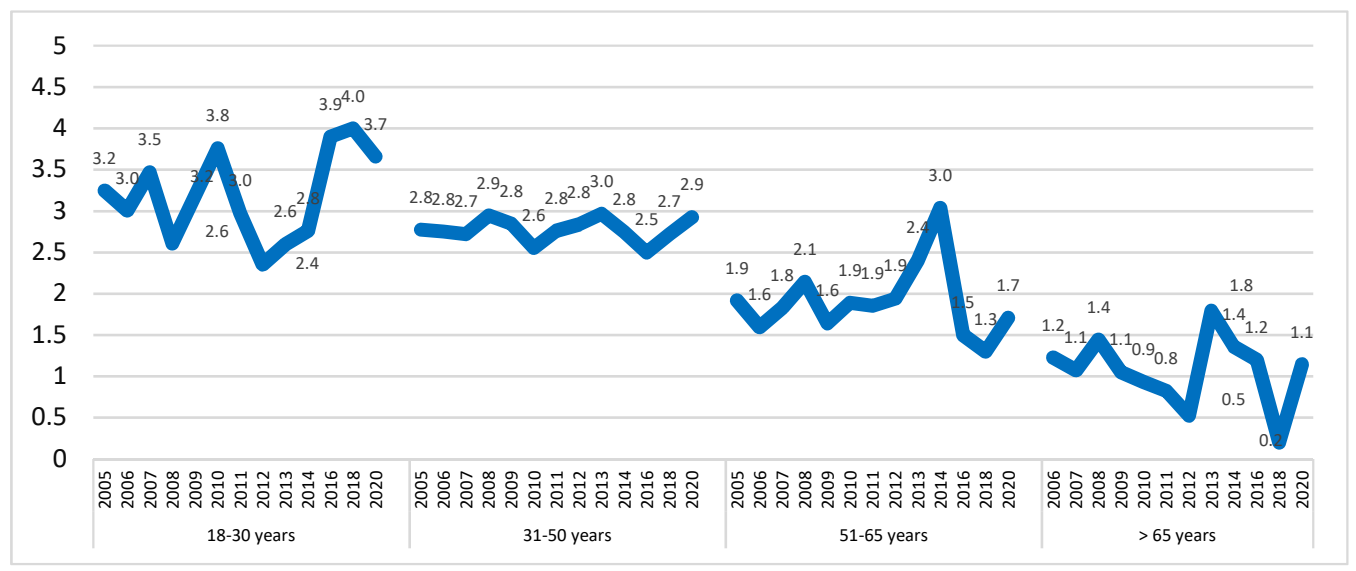

Figure 17. The General Diversity Index based on three weighted positive and three weighted negative statements about diversity-according to age group.

From a party sympathy perspective (see Figure 18), sympathizers of the Green Party (MP) were the most positive towards immigration and ethnic diversity, i.e., $96 \%$ were positive, while $0 \%$ were negative. The Left Party $(\mathrm{V})$ sympathizers were also very positive, although up to $3 \%$ were very negative towards immigration and ethnic diversity. Sympathizers of the Social Democratic Party (S) were mainly positive; among leftist-inclined parties, however, they made up the largest percentage of respondents who were negative towards immigration and ethnic diversity (6\%). Sympathizers of the Centre Party (C) and the Liberals (L) were also mainly positive. The Christian Democrats (KD) sympathizers were mainly positive (50\%), while up to $36 \%$ were undecided and $14 \%$ were negative. Mainly sympathizers of the Sweden Democrats (SD) were negative towards immigration and ethnic diversity $(72 \%)$. Only $6 \%$ were positive, while $21 \%$ were undecided. From a party block perspective, the Red Greens $(\mathrm{S}+\mathrm{MP}+\mathrm{V})$ and the liberal block $(\mathrm{S}+\mathrm{MP}+\mathrm{C}+\mathrm{L})$ were the most positive with $73 \%$, followed by the Alliance block $(M+C+L+K D)$ with $53 \%$, and the conservative block (SD + M + KD) with $27 \%$. 


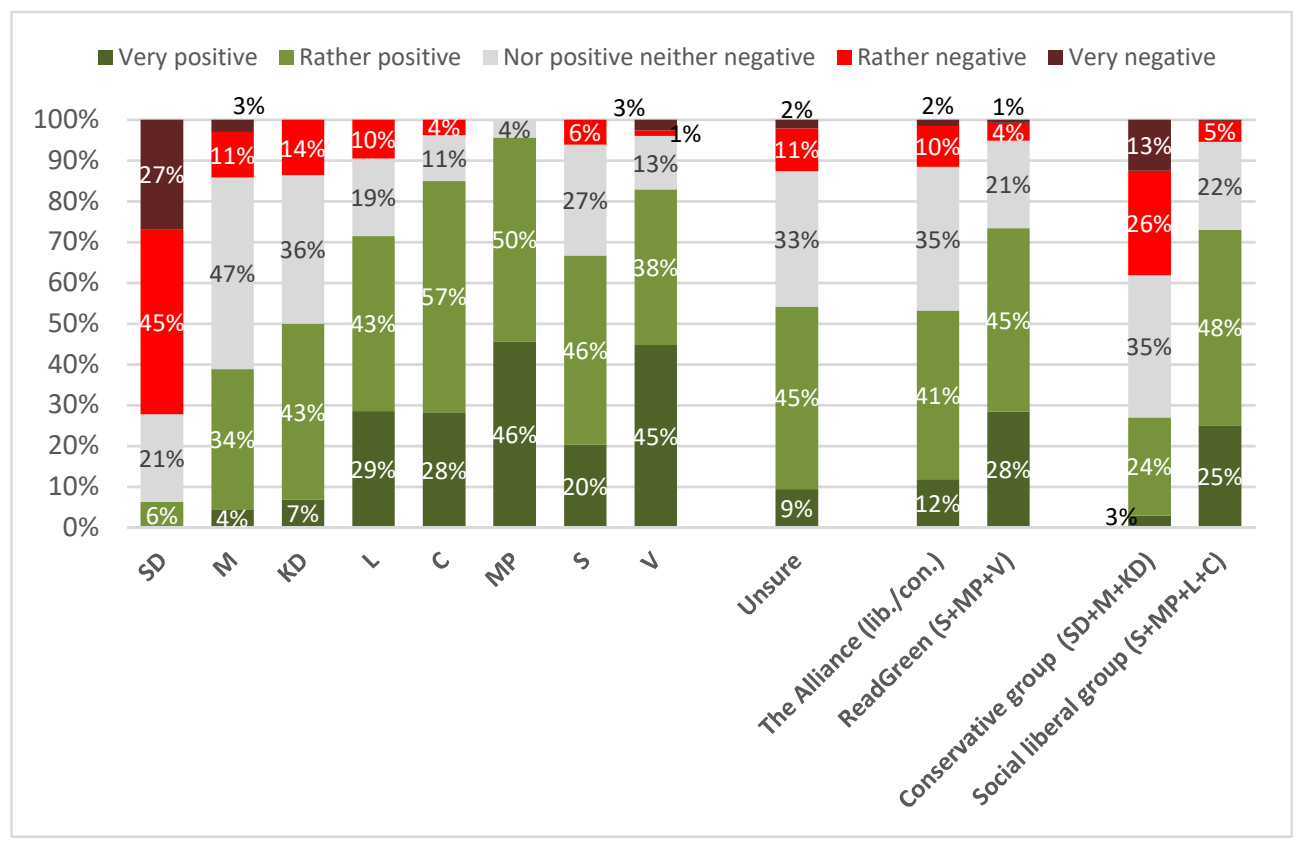

Figure 18. Attitudes towards diversity—based on political party sympathy.

\section{Discussion}

Our aim in this article was to examine changes in attitudes towards immigration and ethnic diversity in Sweden. We did so by analyzing data from 2020 in comparison with data from the previous Diversity Barometer studies. The results show that Swedes have increased contact with people from the Middle East, Asia and Africa. Contact with people from other Nordic counties and the rest of Europe is the most common form of contact with people with foreign backgrounds, although slightly less frequent in comparison to the results from 2018. The majority of respondents had good experiences of studying or working with people with foreign backgrounds. However, those with bad experiences have also increased. Swedes' attitudes towards immigration and ethnic diversity have become more positive, thereby stopping a negative trend that started with the refugee crisis in 2015.

Similar to previous Diversity Barometer studies, the results from 2020 show that positive attitudes are more established among women, younger people, people with higher education, individuals living in larger cities and those who have had more contact with people with foreign backgrounds. Moreover, sympathizers of political parties close to the left wing are more positive to immigration and ethnic diversity. Noteworthy is that sympathizers of the anti-immigration party, Sweden Democrats, stand out as extremely negative towards immigration and ethnic diversity.

Sociological analysis of quantitative data traditionally places great emphasis on universal contextual factors such as economic crises, demographic changes and political changes in the world around us to explain the changes in attitudes to immigration and ethnic diversity (Hjerm 2009). In our analysis of the empirical material, we use concepts and theories such as political correctness, contact theory, strain theory, and a theory about group conflict and group threats. These theories and concepts provide some hypothetical explanations for the observed changes in attitudes.

\subsection{Swedes' Attitudes towards Immigration and Ethnic Diversity from a European Perspective}

Various international studies (European Commission and TNS Opinion \& Social 2015; Meuleman et al. 2009) show that Sweden usually has the most positive attitudes towards immigration in the European Union (EU). In 2011, Sweden had the highest proportion of the population among EU countries that wanted to increase labor immigration from countries outside the EU. Swedes were most the most positive towards the perception that 
immigration enriches the country; as many as $81 \%$ agreed with this statement (Demker 2016). However, results from the Diversity Barometer studies show increasing polarization and general deterioration of attitudes to immigration and ethnic diversity. For example, the results from 2020 show that females have become more positive towards migration, while males are more negative. There is a need to focus on the effects structural transformations at both the national and global levels may have had on the changes in attitude observed in Sweden. From a broader contextual perspective, it is interesting to study whether political debates in recent years on the "death of multiculturalism" in Europe, because of its inherent contradictions, have affected public opinion.

Contextual conditions, such as political discourse, political parties and media reporting, are important for attitudes towards immigration. Attitudes are partly static but are shaped by the narrative in society and in one's own group. The dominant political discourse has conceptualized immigration as a threat to national identity and partly as a threat to the welfare system (Browning 2017). This is reflected in our results, where sympathizers of far-right parties are extremely negative towards migration. Immigration can be seen as a threat because individuals' identities are partly based on ethnic and/or cultural similarity. Common traditions, myths, culture and lineage are seen as something desirable, or even necessary for society to "hold together". The citizens of the country see each other as equal because of their cultural similarity (McLaren 2015). Multiculturalism seems incongruent with some people's basic expectations of what a state should be; it raises concerns among certain sections of the population about how newcomers affect the country.)

Specifically after 2015, many legislative changes have focused on adapting to a common migration and asylum policy within the EU (Europaportalen 2021). Like other EUmember states, Swedish migration policies have gradually become more restrictive, legitimized by the discourse of securitization. The concept "securitization" is used to describe the discourse that pronounces global migration as destabilizing for a host country's cohesion or internal stability, and hence a threat to public order. In other words, the great wave of refugees to Sweden and several EU countries have raised several political and societal challenges regarding human rights, citizenship, power, democracy, and integration. Increasingly, EU countries, including Sweden, place emphasis on their internal security rather than universal rights in relation to refugees. This indicates a shift towards an approach that assumes that migration and, more so, refugees erode national culture, social welfare, and cohesion (Meuleman et al. 2009; Asztalos Morell and Darvishpour 2018). Drawing from a different frame, however, refugees are considered "victims" who we all have a moral obligation to support (Greussing and Boomgaarden 2017). A dislocation of approach is apparent, which means that immigrants and refugees, especially from Islamic countries, are considered to undermine the national culture, social welfare, and unity. This in turn leads to the idea that refugees pose a threat towards the national collective identity. Thus, securitization discourses and restrictive policy can in turn increase negative attitudes towards migration, as observed by the negative trends in the Diversity Barometer after the 2015 refugee influx to Sweden.

\subsection{How to Explain the Deteriorating Attitudes Based on Group Conflict and Group Threat Theory}

The group conflict theory (Quillian 1995) asserts that people are selfish and want to maximize their benefits. Thus, conflicts can be a consequence of groups experiencing incompatible interests that affect the dynamics within and between groups, and the view of each other. Conflicts between groups arise when groups feel they have "incompatible goals" and when they compete for scarce resources, which can be material, status, and power as well as symbolic resources such as the cultural heritage and values. When goals are incompatible, groups or individuals within groups find it legitimate to be hostile to competing groups (Taylor and Moghaddam 1987; Van Knippenberg and Ellemers 1993). Concerns about the redistribution of resources, especially during difficult economic times, could explain the increased negativity towards immigrants and refugees, especially with the influx of refugees during the crisis in 2015. Circumstances such as these can affect 
people who are financially vulnerable to perceiving immigrants as a threat to the labor market and to the welfare system (Lancee and Pardos-Prado 2013).

However, other factors beyond the country's economic situation can also affect attitudes towards immigrants. For example, concerns about security, ideas about cultural differences, values and emotional reactions can also influence attitudes towards immigrants and ethnic diversity (Mayda 2006). Prevailing norms, discourses and the political climate can strengthen individual and collective prejudices. Immigration is perceived as a threat to the national collective identity. As Huysmans (2006) study shows, the influx of asylum seekers has raised questions about security for nations within the European Union. Global migration is blamed for internal insecurity and lapses in national cohesion in different countries. This is especially evident in relation to Muslim refugees, who in the media and political discourses are considered a threat to European civilization and culture. Refugees are thus judged as a threat to welfare systems and Western values such as equality, democracy and responsibility (Darvishpour and Månsson 2019).

The escalating terrorist activity in recent years carried out by Islamist fundamentalist groups inside and outside Europe certainly has a connection with the perception that immigration, especially from the Middle East and North Africa, poses a threat. Some investigations show that the terrorist attacks in 2001 against the World Trade Center in USA had a major negative impact on the European image and attitudes towards Muslims (Larsson 2005; Kolankiewicz 2015). The results of the Diversity Barometer 2016 and 2018 show that attitudes to immigrants from the Middle East and North Africa were the most negative. The results also show that $43 \%$ of the respondents thought that men from the Middle East posed a danger to Swedish culture. It is important to note that the population's attitudes to diversity have become more negative about other cultures and religions, especially Islam. The results also show that almost half of the respondents, women as well as men, argued that not all religions had the same value, and this was considered especially true for Islam (Ahmadi et al. 2015, 2020b). Thus, many people see multiculturalism as the main obstacle to integration of people with foreign backgrounds into the new national community. Issues of economic and cultural threat may therefore explain the complex problem of xenophobia (Hjerm and Nagayoshi 2011).

Furthermore, the successful political mobilization among right-wing national movements can be a contributing factor to increased prejudices and negative attitudes to immigration and ethnic diversity (Bohman 2011). The EU parliamentary elections in 2014 and 2019 and the Swedish parliamentary elections in 2014 and 2018 show a significant increase in right-wing populist and anti-immigration parties (Berg and Oscarsson 2015; Statistics Sweden 2018; Europaparlamentet 2019).

In summary, based on group conflict theory, Perry (2001) asserts that structural and institutional discrimination of minorities, based on ethnicity, religion, race, etc., gives rise to individual intolerance among large sections of the population. This in turn leads to consolidation of power imbalance and discriminatory power relations in society. Some international studies (Bobo 1988) show that negative attitudes to immigration and ethnic diversity emanate from feelings of powerlessness. This quite often creates intolerant societies and groups because people feel excluded, marginalized and neglected-in other words, people feel that they are victims of society. Moreover, periods of economic stagnation and crises often put vulnerable groups in conflict with each other (Bobo 1988). The threat need not, of course, be real, but prejudices with symbolic and cultural characteristics make it real for those who perceive it.

\subsection{How to Explain Negative Attitudes Based on Contact Theory}

Our results show that attitudes towards immigration and ethnic diversity are partly related to the respondents' experience of contact with immigrants. People who have more contact with immigrants at work and school are more positive compared to those with less contact with immigrants. This is in line with survey results from previous Diversity Barometers surveys, and can be explained with the help of contact theory. Allport (1954) 
formulated the idea that where there is no personal relationship and contact between members of minority and majority groups, the risk of negative attitudes towards each other arises. This can explain why people with less experience and contact with immigrants are more negative towards immigration and ethnic diversity. However, a condition for positive outcomes is that contact between groups takes place under similar conditions, with similar templates. For this reason, segregation can further reinforce negative attitudes (Semyonov and Glikman 2009).

\subsection{Strain Theory and the Effect of Prejudice and Stigmatization}

Xenophobia and ethnocentrism can be the result of prejudice. Prejudice results from a simplified image or a way of thinking based on an individual's perceptions. Individuals' sociocultural background factors have great importance in the development of prejudice. However, prejudice can also be a result of contextually bound collective ideas, and can be the basis for negative attitudes to the other (Brown 1988). This means that increased contact with, and knowledge of, immigrants can alleviate prejudice and reduce xenophobic attitudes. This may explain why people with greater contact and experience with immigrants normally have positive attitudes towards immigrations and ethnic diversity, as shown by the Diversity Barometer surveys.

According to strain theory, which focuses on structural change and its significance in the individual's attitudes (Blomberg 2010), feelings of insecurity and frustration over personal losses and failures lead to strong and extremely negative attitudes and behaviors, which are sometimes directed at a group other than the source of frustration. Moreover, individual's stress can be heightened by the feeling of powerlessness, and the inability to point out a clear source of frustration. In such cases, the target of the individual's negative attitudes becomes someone nearby, or someone perceived as weaker (Einarsson 1996). This seems to be the cause of the negative attitudes among people with lower education levels, and those living in smaller communities. On the contrary, people with higher education levels often have a permanent/secure employment situation, and are therefore less threatened by immigration.

Additionally, strain theory has a close connection to the scapegoat theory that postulates that one designates others as scapegoats; the scapegoats thus bear the blame for one's problems and misfortunes. Historically, categorizations based on markers such as gender, class, religion, race, ethnicity, sexual orientation or preference and political beliefs have been used to distinguish "scapegoats" from the majority (Brown 2015). Some studies (Brown 1988) emphasize that during hard social and economic conditions, frustration can manifest itself through increased prejudice against other ethnic groups. People become dissatisfied when they perceive a difference between what they actually have and what they think they should or could have. This increases their frustrations and negativity towards others whom they perceive stand in the way for goal attainment.

According to some researchers (Strömbäck et al. 2017; Frost 2007), xenophobic political movements alone do not create anti-immigrant discourses. Opinion leaders and the media contribute to the negative discourse depending on how they describe immigration. By pointing out immigrants as scapegoats, for example, they affect the opinions of vulnerable groups systematically affected by economic and structural change. This leads to a consolidation of the power imbalance and discriminatory power relations between immigrants and natives. Media, authorities, researchers, and opinion leaders normally emphasize discourse on conflict-laden issues, rather than discourse on well-functioning relationships among people in residential areas, schools and workplaces. Thus, the image spread by the media and other opinion leaders does not give a balanced picture of multicultural relations.

\subsection{A Tendency of Highly Educated People to Be Politically Correct}

Another finding in all studies performed in the series of Diversity Barometer studies is that people with lower education express the most negative attitudes towards immigration 
and ethnic diversity. People with higher levels of education tend to show more positives attitudes. Other studies in Sweden and Europe have reported similar findings (Mella 2011; Hainmueller and Hiscox 2007). One explanation may be that those with a higher level of education have closer contact with immigrants who have established themselves in their new home country, and that they have a greater anti-racist understanding and that they are more likely to have traveled abroad. However, another plausible explanation is that people with higher levels of education are more inclined to be politically correct when answering questions about their attitudes towards immigrants. Mella (2011) states that higher education provides access to a broader international context that favors more open attitudes, as well as access to more abstract thinking about the causes and consequences of migration processes. Additionally, higher education provides access to an intellectual environment, where the tendency of social desirability is common especially in relation to attitudes towards people in vulnerable situations. Mella (2011) asserts that highly educated people not only understand the causes of immigration, but also easily hide their negative attitudes. Thus, they are more likely to be politically correct when talking about their attitudes towards immigration and ethnic diversity.

\section{Conclusions}

This study shows that Swedes' attitudes towards immigration and ethnic diversity have become more positive. However, attitudes are still negative when compared to the results prior to 2016. The refugee influx in 2015 seems to have had an effect on the currently observed trends. We have provided an analysis based on a group conflict and group threat theory among other perspectives. However, one interesting hypothesis to consider in the future studies is whether the explanation for increased negativity towards immigrants can be found in the transition from an industrial to a post-industrial economy, and the development of neoliberal politics (Rydgren 2017). Rydgren believes that that this hypothesis can help explain why racist views and negative attitudes towards immigration have grown stronger in Sweden and Europe. According to Rydgren's supposition, times of crisis strengthen xenophobia. In today's global society with all its anxiety and fear, people tend to look for security in the old, local culture. Rydgren's studies show that globalization processes affect local conditions in varied ways. It is therefore interesting to examine how globalization can affect attitudes to immigration and ethnic diversity in the Swedish context.

From a sociological and social work perspective, transition processes such as unemployment, insecurity and exclusion are important factors that should be examined when studying increased anti-immigrant attitudes and support for anti-immigrant policies. In the last two decades, neoliberal globalization has had a strong effect on welfare systems in countries around the world as well as in Sweden (Fook 2002; Stepney and Popple 2008). It is therefore equally important to study the possible effects of reductions in welfare benefits on attitudes to ethnic diversity and immigration.

For a deeper understanding of the current attitudes towards immigration in Sweden and the EU, it is important to increase knowledge about the reasons for the increased negative attitudes towards immigration. Previous studies have often drawn attention to how economic problems can affect the degree of racism, intolerance and skepticism towards immigrants. However, the Diversity Barometer shows that a negative assessment of the cultural consequences of immigration (in addition to the economic effects) is one reason for the deteriorating attitudes towards immigration. Hainmueller and Hopkins (2014) raise the same concern, yet this issue is seldom highlighted. According to Oesch (2008), the negative attitudes of the working class towards migrants and their decision to vote for right-wing populist parties are mainly due to considering the nation's culture at threat from immigration. Similar to Hainmueller and Hiscox (2007), this study shows that people with higher education have more positive experiences with and attitudes towards immigration and diversity as compared to those with lower education. These differences could be more suited to post-material values and perceptions of multiculturalism. This 
could also explain why women and young people are more positive towards immigration and diversity, yet they often have a worse economic situation compared to men and middleaged people. A qualitative study of attitudes to immigration and diversity among different groups of people in both Sweden and the EU could illustrate and deepen our knowledge of the complex causes of deteriorating attitudes to diversity and immigration.

Author Contributions: Conceptualization, F.A.; methodology, F.A.; software, outsourced.; formal analysis, J.S.M., F.A. and M.D.; investigation/data collection, outsourced.; data curation, outsourced.; writing-original draft preparation, J.S.M., F.A. and M.D.; writing—review and editing, J.S.M., F.A. and M.D.; visualization, J.S.M., F.A. and M.D.; supervision, F.A.; project administration, F.A. and J.S.M.; funding acquisition, F.A. All authors have read and agreed to the published version of the manuscript.

Funding: This research received no external funding.

Institutional Review Board Statement: Ethical review and approval were waived for this study because the survey was anonymous without personal identifiable information.

Informed Consent Statement: Informed consent was obtained from all subjects in the study. An anonymous survey questionnaire was used, and respondents chose to reply or not. No personal identifiable information was collected.

Data Availability Statement: The data supporting the reported results are archived at the Faculty of Health and Occupational Studies, University of Gävle. The data are not publicly available.

Conflicts of Interest: The authors declare no conflict of interest.

\section{References}

Ahmadi, Fereshteh, Mehrdad Darvishpour, Nader Ahmadi, and Irving Palm. 2020a. Diversity barometer: Attitude change in Sweden. Nordic Social Work Research 10: 21-23. [CrossRef]

Ahmadi, Fereshteh, Mehrdad Darvishpour, and Irving Palm. 2020b. Changes regarding attitudes towards ethnic and cultural diversity in Sweden. The diversity barometer (2005-2018). International Journal of Social Science Studies 8: 1-16. [CrossRef]

Ahmadi, Fereshteh, Orlando Mella, Irving Palm, and Mehrdad Darvishpour. 2015. Mångfaldsbarometern: Tio år av attitydmättningar i Sverige [The Diversity Barometer: Ten Years of Attitude Surveys in Sweden]. Gävle: Gävle University Press.

Ahmed, Ali, and Mats Hammarstedt. 2008. Discrimination in the Rental Housing Market. A Field Experiment on the Internet. Journal of Urban Economics 64: 362-72. [CrossRef]

Aldén, Lina, Mats Hammarstedt, and Emma Neuman. 2015. Ethnic Segregation, Tipping Behaviour, and Native Residential Mobility. International Migration Review 49: 36-69. [CrossRef]

Allport, Gordon. 1954. The Nature of Prejudice. Cambridge: Addison-Wesley.

Asztalos Morell, Ildikó, and Mehrdad Darvishpour. 2018. The securitization of asylum-seeking in Sweden after 2015 in light of experiences of asylum-seeking adolescent girls with roots in Afghanistan. In The Migration Crisis? Criminalization, Security and Survival. Edited by Dina Siegel and Veronika Nagy. Haag: Eleven International Publishing, pp. 363-89.

Berg, Linda, and Henrik Oscarsson. 2015. Supervalåret 2014. Demokratistatistik Rapport 20. Stockholm: Statistics Sweden. Available online: https:/ / www.scb.se/contentassets/7fbb57f3b2ca4a36aae16345c240e475/me0106_2014a01_br_me09br1503.pdf (accessed on 15 October 2021).

Blomberg, Tom. 2010. Robert Agnew's General Strain Theory. Tallahassee: College of Criminology and Criminal Justice, Florida State University. Available online: http:/ / www.criminology.fsu.edu/crimtheory/agnew.htm (accessed on 20 December 2014).

Bobo, Lawrence. 1988. Group conflict, prejudice and the paradox of contemporary racial attitudes. In Eliminating Racism. Profiles in Controversy. Edited by Phyllis Katzs and Dalmas Taylor. New York: Springer, pp. 85-114.

Bohman, Andrea. 2011. Articulated antipathies. Political influence on anti-immigrant attitudes. International Journal of Comparative Sociology 52: 457-77. [CrossRef]

Brown, Rupert. 1988. Group Processes. Dynamics within and Between Groups. Oxford: Blackwell Publishers.

Brown, Wyatt. 2015. An Intersectional Approach to Criminological Theory: Incorporating the Intersectionality of Race and Gender into Agnew's General Strain Theory. Ralph Bunche Journal of Public Affairs 4: 6. Available online: https://digitalscholarship.tsu.edu/ cgi/viewcontent.cgi?article=1027\&context=rbjpa (accessed on 20 August 2021).

Browning, Christopher S. 2017. Security and migration: A conceptual exploration. In Handbook om Migration and Security. Edited by P. Bourbeau. Cheltenham: Edward Elgar, pp. 39-57.

Bursell, Moa. 2012. Ethnic Discrimination, Name Change and Labor Market Inequality: Mixed Approaches to Ethnic Exclusion in Sweden. Ph.D. dissertation, Stockholm University, Stockholm, Sweden. Available online: http://su.diva-portal.org/smash/get/ diva2:561919/FULLTEXT01.pdf (accessed on 15 October 2021). 
Crawley, Heaven, and Simon Mcmahon. 2016. Beyond Fear and Hate: Mobilising People Power to Create a New Narrative on Migration and Diversity. Coventry: Coventry University. [CrossRef]

Darvishpour, Mehrdad, and Niclas Månsson. 2019. Ensamkommandes Upplevelser och Professionellas Erfarenheter. Integration, Inkludering $\mathcal{E}$ Jämställdhet. Malmö: Liber.

Darvishpour, Mehrdad, and Charles Westin, eds. 2021. Migration och Etnicitet: Perspektiv på Mångfald Sverige. Lund: Studentlitteratur.

Demker, Marie. 2016. De generösa svenskarna? En analys av attityder till invandring och invandrare i Sverige. [The generous Swedes? An analysis of attitudes towards immigration and immigrants in Sweden]. Norsk Statsvitenskapelig Tidskrift 32: 186-96. [CrossRef]

Dias, Sónia, Ana Gama, Helena Cargaleiro, and O. Maroa Martins. 2012. Health workers' attitudes towards immigrant patients: A cross-sectional survey in primary health care services. Human Resources for Health 10: 1-6. [CrossRef]

Einarsson, Charlotta. 1996. Konflikter Mellan Grupper. Teorier om Intergruppskonflikter. FOG Rapport 33. Linköping: Institutionen för Beteendevetenskap, Linköpings Universitet.

Ericson, M. 2018. Sweden has been Naïve: Nationalism, protectionism and securitisation in response to the refugee crisis of 2015. Social Inclusion 6: 95-102. [CrossRef]

Europaportalen. 2021. Sverige \& EU [Sweden and the European Union]. Europaportalen. Available online: https: / / www.europaportalen. se/teman/sverige-och-eu (accessed on 4 October 2021).

Europaparlamentet. 2019. Europeiska Valresultat 2019 [European Election Results 2019]. Europaparlamentet. July 2. Available online: https:/ / www.europarl.europa.eu/election-results-2019/sv (accessed on 19 April 2021).

European Commission and TNS Opinion \& Social. 2015. Public Opinion in the European Union. Standard Eurobarometer 83. Brussels: European Commission. Available online: https://op.europa.eu/en/publication-detail/-/publication/a1216955-f7e9-11e5-b1f9 -01aa75ed71a1/language-en (accessed on 15 October 2021).

Fook, Jan. 2002. Social Work. Critical Theory and Practice. London: Sage.

Frost, D. 2007. The "enemy within"? Asylum, racial violence and "race hate" in Britain today. Twenty-First Century Society 2: 227-48. [CrossRef]

Greussing, Esther, and Hajo Boomgaarden. 2017. Shifting the refugee narrative? An automated frame analysis of Europe's 2015 refugee crisis. Journal of Ethnic and Migration Studies 43: 1749-74. [CrossRef]

Hagelund, Anniken. 2020. After the refugee crisis: Public discourse and policy change in Denmark, Norway and Sweden. Comparative Migration Studies 8: 1-17. [CrossRef]

Hainmueller, Jens, and Daniel J. Hopkins. 2014. Public Attitudes toward Immigration. Annual Review of Political Science 17: 225-49. [CrossRef]

Hainmueller, Jens, and Michael J. Hiscox. 2007. Educated preferences. Explaining attitudes toward immigration in Europe. International Organization 61: 399-442. [CrossRef]

Hjerm, Mikael. 2009. Anti-immigrant attitudes and cross-municipal variation in the proportion of immigrants. Acta Sociologica 52: 47-62. [CrossRef]

Hjerm, Mikael, and Kikuko Nagayoshi. 2011. The composition of the minority population as a threat. Can real economic and cultural threats explain xenophobia? International Sociology 26: 815-43. [CrossRef]

Holloway, Kerrie, and Amy Leach. 2020. Public Narratives and Attitudes towards Refugees and Other Migrants: Sweden Country Profile. London: ODI.

Huysmans, Jef. 2006. The Politics of Insecurity. Fear, Migration and Asylum in the EU. Hoboken: Taylor \& Francis.

Kolankiewicz, Marta. 2015. Anti-Muslim Violence and the Possibility of Justice. Ph.D. dissertation, Lund University, Lund, Sweden.

Lancee, Bram, and Sergi Pardos-Prado. 2013. Group conflict theory in a longitudinal perspective. Analyzing the dynamic side of ethnic competition. International Migration Review 47: 106-31. [CrossRef]

Larsson, Göran. 2005. The impact of global conflicts on local contexts. Muslims in Sweden after 9/11. The rise of islamophobia or new possibilities? Islam and Christian-Muslim Relations 16: 29-42. [CrossRef]

Mayda, Anna. Maria. 2006. Who is against immigration? A cross-country investigation of individual attitudes toward immigrants. The Review of Economics and Statistics 88: 510-30. [CrossRef]

McLaren, Lauren. 2015. Immigration and Perceptions of National Political Systems in Europe. Oxford: Oxford University Press.

Mella, Orlando. 2011. Mångfaldsbarometern. Sju år av attitydmätningar. Sociologisk Forskning 48: 45-53.

Meuleman, Bart, Eldad Davidov, and Jaak Billiet. 2009. Changing attitudes toward immigration in Europe, 2002-2007. A dynamic group conflict theory approach. Social Science Research 38: 352-65. [CrossRef] [PubMed]

Mulhall, Joe, and Safya Khan-Ruf, eds. 2021. State of Hate: Far-Right Extremism in Europe 2021. London: HOPE not Hate.

Novus. 2014. Attityd och Kunskap om Invandring. Available online: https:/ fores.se/wp-content/uploads/2014/12/FINAL-Novus_ Fores_Migration_Presentation-20141218-16.12.pdf (accessed on 4 October 2021).

Oesch, Daniel. 2008. Explaining Workers' Support for Right-Wing Pupulist Parties in Western Europe: Evidence from Austria, Belgium, France, Norway, and Switzerland. International Political Science Review 29: 347-73. [CrossRef]

Perry, Barbara. 2001. In the Name of Hate. Understanding Hate Crime. London and New York: Routledge.

Pitkänen, Pirkko, and Satu Kouki. 2002. Meeting foreign cultures: A survey of the attitudes of Finnish authorities towards immigrants and immigration. Journal of Ethnic and Migration Studies 28: 103-18. [CrossRef] 
Quillian, Lincoln. 1995. Prejudice as a response to perceived group threat. Population composition and anti-immigrant and racial prejudice in Europe. American Sociological Review 60: 586-611. Available online: http://www.jstor.org/stable/2096296 (accessed on 19 April 2021). [CrossRef]

Rydgren, Jens, ed. 2017. The Oxford Handbook of the Radical Right. Oxford: Oxford University.

Schütze, Carolin. 2020. Attitudes matter-welfare work and migration in Sweden. Migration Studies 8: 424-54. [CrossRef]

Semyonov, Moshe, and Anya Glikman. 2009. Ethnic residential segregation, social contacts, and anti-minority attitudes in European societies. European Sociological Review 25: 693-708. [CrossRef]

Statistics Sweden. 2018. Riksdagsvalet 2018 på Karta. Available online: https:/ /www.scb.se/contentassets/5f130880a8da4c17981f2cd3 7251110c/valresultat-rv-kommunredovisning-kartor_2018.pdf (accessed on 19 April 2021).

Statistics Sweden. 2021. Utrikes Födda I Sverige. [Foreign-Born Population in Sweden]. Available online: https://www.scb.se/hittastatistik/sverige-i-siffror/manniskorna-i-sverige/utrikes-fodda/ (accessed on 19 April 2021).

Statistics Sweden. n.d. Population by Age and Sex. Year 1860-2020. Available online: https:/ /www.statistikdatabasen.scb.se/pxweb/ en/ssd/START_BE_BE0101_BE0101A/BefolkningR1860N/ (accessed on 18 October 2021).

Stepney, Paul, and Keith Popple. 2008. Social Work and the Community: A Critical Context for Practice. New York: Palgrave Macmillan.

Strömbäck, Jesper, Felicia Andersson, and Evelina Nedlund. 2017. Invandring i Medierna. Hur Rapporterades Svenska Tidningar Åren 2010-2015? Stockholm: Delmi.

Taylor, Donald M., and Fathali M. Moghaddam. 1987. Theories of Intergroup Relations. International Social Psychological Perspectives. New York: Preager Publishers.

Valmyndigheten. 2021. Valresultat 2018 [Election Results 2018]. Valmyndigheten. June 3. Available online: https://www.val.se/ valresultat/riksdag-region-och-kommun/2018/valresultat.html (accessed on 4 October 2021).

Van Knippenberg, D. V., and N. Ellemers. 1993. Strategies in intergroup relations. In Group Motivation. Social Psychological Perspectives. Edited by M. A. Hogg and D. Abrams. New York: Harvester Wheatsheaf. 